\title{
Article
}

\section{Long-Term Results of a Standard Algorithm for Intravenous Port Implantation}

\author{
Ching-Feng $\mathrm{Wu}^{1,2,+}{ }^{1}$ Jui-Ying Fu ${ }^{2,3, \dagger}$, Chi-Tsung Wen ${ }^{2,4}$, Chien-Hung Chiu ${ }^{1,2}$, Ming-Ju Hsieh ${ }^{1,2}$, Yun-Hen Liu ${ }^{1,2}$, \\ Hui-Ping Liu ${ }^{1,2}$ and Ching-Yang $\mathrm{Wu}^{1,2, *}$
}

1 Department of Surgery, Thoracic and Cardiovascular Surgery Division, Chang Gung Memorial Hospital, Linkou 333423, Taiwan; maple.bt88@gmail.com (C.-F.W.); b9102067@cgmh.org.tw (C.-H.C.); hsiehmj2@cgmh.org.tw (M.-J.H.); 15710111@cgmh.org.tw (Y.-H.L.); tpeclcra@gmail.com (H.-P.L.)

2 Medical Department, Medical College, Chang Gung University, Taoyuan 333323, Taiwan; juiing0917@hotmail.com (J.-Y.F.); ctwen2001@gmail.com (C.-T.W.)

3 Pulmonary and Critical Care Medicine, Department of Internal Medicine, Chang Gung Memorial Hospital, Linkou 333423, Taiwan

4 Thoracic and Cardiovascular Surgery Division, Department of Surgery, New Taipei Municipal Tu-Cheng Hospital, New Taipei City 236017, Taiwan

* Correspondence: wu.chingyang@gmail.com; Tel.: +886-3-328-1200 (ext. 8150); Fax: +886-3-328-5818

+ Contributed equally to this manuscript.

check for updates

Citation: Wu, C.-F.; Fu, J.-Y.; Wen, C.-T.; Chiu, C.-H.; Hsieh, M.-J.; Liu, Y.-H.; Liu, H.-P.; Wu, C.-Y. Long-Term Results of a Standard Algorithm for Intravenous Port Implantation. J. Pers Med. 2021, 11, 344. https://doi.org/ 10.3390/jpm11050344

Academic Editor: William Duddy

Received: 11 March 2021

Accepted: 21 April 2021

Published: 24 April 2021

Publisher's Note: MDPI stays neutral with regard to jurisdictional claims in published maps and institutional affiliations.

Copyright: (c) 2021 by the authors. Licensee MDPI, Basel, Switzerland. This article is an open access article distributed under the terms and conditions of the Creative Commons Attribution (CC BY) license (https:// creativecommons.org/licenses/by/ $4.0 /)$.

\begin{abstract}
Intravenous ports serve as vascular access and are indispensable in cancer treatment. Most studies are not based on a systematic and standardized approach. Hence, the aim of this study was to demonstrate long-term results of port implantation following a standard algorithm. A total of 2950 patients who underwent intravenous port implantation between March 2012 and December 2018 were included. Data of patients managed following a standard algorithm were analyzed for safety and long-term outcomes. The cephalic vein was the predominant choice of entry vessel. In female patients, wire assistance without use of puncture sheath was less likely and echo-guided puncture via internal jugular vein (IJV) with use of puncture sheath was more likely to be performed, compared to male patients $(p<0.0001)$. The procedure-related complication rate was $0.07 \%$, and no pneumothorax, hematoma, catheter kinking, catheter fracture, or pocket erosion was reported. Catheter implantations by echo-guided puncture via IJV notably declined from $4.67 \%$ to $0.99 \%$ $(p=0.027)$. Mean operative time gradually declined from $37.88 \mathrm{~min}$ in 2012 to $23.20 \mathrm{~min}$ in 2018 . The proposed standard algorithm for port implantation reduced the need for IJV echo-guided approach and eliminated procedure-related catastrophic complications. In addition, it shortened operative time and demonstrated good functional results.
\end{abstract}

Keywords: intravenous port; totally implantable vascular access device; standard algorithm

\section{Introduction}

An intravenous port provides secure vascular access for delivery of treatment in cancer patients. Major issues related to intravenous port implantation include first attempt success rate [1-3] and peri-operative and late complications [4-7]. Several native vessels can be used as the entry vessel for chest port insertion, including the cephalic vein [2,3], deltoid branch of the thoracoacromial vein [8], the axillary vein [1,9], the internal jugular vein [3], the external jugular vein [2], the left brachiocephalic vein [10,11], and the subclavian vein [12-14]. However, different implantation methods are used for different target vessels and varying long-term results have been reported. There has been no consensus on recommendations because most clinical practitioners just consider intravenous ports as vascular access instead of seeing them as part of an integrated cancer treatment plan. As cancer treatment has improved, the possibility of secondary malignancy and the need for port re-implantation have gradually increased. This highlights the important role of patients' native vessels, even with suboptimal quality, and of preserving the entry vessels 
for port re-implantation. Therefore, surgeons need an implantation recommendation that not only has good functional result but is also easy to follow and allows quantifiable quality control. From the literature review, vessel cutdown has been shown to have a low immediate complication rate [15] because the patient's native vessel is explored and can be directly visualized for catheter implantation. The cephalic vein is the target vessel for vessel cutdown because of its superficial location. However, alternative entry vessels may be needed if the cephalic vein is absent or if the vessel has a small caliber or a tortuous configuration. In order to preserve the entry vessel and resolve these difficulties, a standard algorithm has been proposed [16].

Four major improvements, which differ from previous studies, have been introduced. First, establish standard operation procedure and utilization priority of entry vessels. This is easier for inexperienced surgeons to follow and resolves difficulties when a target vessel cannot be easily identified. Second, use endovascular techniques to deal with target vessels of suboptimal quality, such as those of small-caliber or tortuous route $[8,16]$. This preserves patients' native vessels and reduces difficulties during re-implantation. Echo-guided puncture at high neck areas, i.e., thyroid cartilage level, to reach the internal jugular vein (IJV) is only reserved for patients without accessible native vessels. Third, completely avoid subclavian vein and lower neck IJV puncture. This eliminates iatrogenic arterial puncture [13,14], hemothorax [17], and mediastinal hematoma [18]. In addition, pneumothorax $[13,14]$ and catheter fracture related to pinch-off syndrome [19] are completely avoided. Fourth, enforce quality control by the addition of quantified catheter length formulae [20] for catheter length estimation and intra-operative fluoroscopy [21].

Based on these improvements, the standard algorithm for port implantation not only utilizes entry vessels more efficiently but also minimizes variations in implantation as a result of quantified implantation quality control. Our previous study showed good short-term results [16] and, in this study, we further analyzed long-term results of the standard algorithm for intravenous port implantation, not only to prove its reproducibility in various clinical scenarios but also to provide easy-to-follow recommendations for port implantation.

\section{Materials and Methods}

\subsection{Patient Population}

A total of 3144 patients who underwent intravenous port implantation between March 2012 and December 2018 at Chang Gung Memorial Hospital were enrolled. The patients' disposition diagrams are shown in Figure S1. There were 2950 consecutive patients who underwent port implantation via the superior vena cava (SVC) route or the inferior vena cava (IVC) route (Table S1). This study was approved by the Institutional Review Board under the approval numbers 20150929B0 and 201800329B0. Patients' signed, informed consent was obtained before enrollment. This retrospective study was supported by Chang Gung Medical Foundation under grant number CMRPG5G0131.

\subsection{Standard Algorithm for Port Implantation}

In order to better preserve the entry vessel and to improve convenience of nursing care, the SVC route was preferred (Figure 1). The IVC route was reserved for patients with SVC syndrome. Potential entry vessels for the SVC route were the cephalic vein, the deltoid branch of the thoracoacromial vein, and the IJV. Potential entry vessels for the IVC route were the greater saphenous vein (GSV) and the femoral vein. The pocket sites for port embedding of SVC and IVC ports were the fascia of the pectoralis major muscle and the abdominal rectus muscle near the anterior superior iliac spine (ASIS), respectively. Intra-operative fluoroscopy was used for catheter guidance and confirmation of tip location. Postoperative assessment of catheter-nut angle and catheter tip location on chest plain film was done in all patients. 
Identified patients' clinical scenarios

DRoute: SVC route versus IVC route

QSide: Right versus Left

Principles of standard algorithm

a. Minimized procedure related complications

( SVC route first

2 No subclavian vein punclure

3 No lower neck puncture for internal jugular vein

4 Vessel cutdown first (SVC: cephalic vein; IVC: Greater saphenous vein)

b. Preserve entry vessel

(1 Cephalic vein first

2 Deltoid branch of thoraco-acromial vein as alternative route

3 Endovascular technique (metallic wire cannulation)/ Road mapping guidance (intra-operation venogram)

4 Preserve superficial vessel (SVC route: IJV; IVC route: femoral vein) for emergent use

c. Standardized operation procedure

(1) Incision

SVC: Sub-clavicular incision ( for vessel exploration and pocket creation)

IVC: Sub-inguinal incision ( for vessel exploration)

Transverse incision above anterior inferior iliac spine ( for pocket creation)

2 Landmark reference:

SVC: Coracoid process of scapula

IVC: parallel line $3 \mathrm{~cm}$ below inguinal skin fold

Medial inferior aspect of palpable inguinal femoral artery pulsation site

3 Adequate pocket size

4 Fixed port on muscular fascia that had underlying bony structure

( SVC: pectoralis major muscle/ thoracic cage; IVC: abdominal rectus muscle/ anterior inferior iliac spine)

5 Intra-operation fluoroscopy guidance

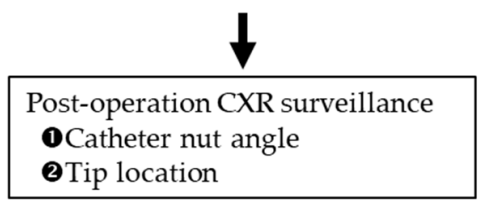

Figure 1. Standard algorithm of intravenous port implantation.

\subsection{Surgical Method}

For SVC ports, the anatomic landmark was the coracoid process of the scapulae. After aseptic preparation, the coracoid process was identified and local anesthesia applied at this point. A 2-cm incision was made and deepened to the deltopectoral groove. Vessel cutdown was used for vessels with adequate caliber and smooth configuration. Wire assistance without puncture was used for vessels with adequate vessel caliber but with tortuous path. Wire assistance with puncture was used for vessels with both small-caliber and tortuous path. For patients in whom manual wire cannulation was difficult, the cannulation route was clarified on intra-operative venography. For patients without accessible cephalic or deltoid branch of the thoracoacromial vein, the IJV served as a rescue entry vessel, and echoguided IJV high-neck puncture was used for implantation. For IVC ports, the anatomic landmarks were the anterior inferior iliac spine and the pubic tubercle, and two small incisions were made at the anterior inferior iliac spine and the subinguinal area. Greater saphenous vein exploration and catheter implantation were done via the subinguinal incision, and the port was fixed over the abdominal rectus fascia via incision at the ASIS.

\subsection{Follow-Up and Postoperative Surveillance}

All patients underwent plain chest radiography following the procedure in order to confirm the catheter tip location, catheter-nut angle, and integrity of the implanted port. Catheter-nut angle and tip location measurements were recorded in a picture archiving 
and communication system (PACS). All patients returned to the outpatient department for follow-up at 3-month intervals and underwent flushing for maintenance. Functional period was defined as the time during which the implanted port maintained normal function. For patients without complications, this was from implantation date to date of removal or last follow-up. For those with complications needing re-intervention, it was from implantation date to date of re-intervention.

\subsection{Statistics}

All collected data were first analyzed using univariate analysis. Categorical variables were compared using chi-square test or Fisher's exact test. A $p$-value of less than 0.05 was considered statistically significant. Confidence intervals (CI) were assumed to have a coverage probability of $95 \%$. Complication rates are presented as episode percentage among the whole population and incidence is presented as episode per 1000 catheter days. Loess smooth and linear regression curve models were deployed for analysis of operation time variation. All analyses were performed using SAS, version 9 (SAS Institute, Cary, NC, USA).

\section{Results}

\subsection{Sex Differences}

The mean age of female patients was younger than that of male patients ( $57.3 \pm 12.8$ years vs. $59.6 \pm 12.8$ years, $p<0.0001$ ) (Table 1 ). More male patients had head and neck cancer $(p<0.0001)$, and more female patients had thoracic malignancy $(p<0.0001)$. In addition, male patients had greater mean body height $(165.8 \pm 7.2 \mathrm{~cm}$ vs. $154.9 \pm 6.9 \mathrm{~cm}, p<0.001)$ and mean body weight $(64.4 \pm 11.8 \mathrm{~kg}$ vs. $55.8 \pm 10.4 \mathrm{~kg}, p<0.001)$ compared to female patients, though mean BMI was similar for the two genders $(p=0.2941)$. The left-side approach was used more in female patients. Operation methods differed significantly between male and female patients $(p<0.0001)$. Mean catheter-nut angle of male and female patients was $169.7 \pm 7.7^{\circ}$ and $170.0 \pm 7.2^{\circ}$, respectively $(p=0.1926)$. Deeper mean catheter tip location was noted in female patients $(1.4 \pm 1.5 \mathrm{~cm}, p<0.0001)$. Mean functional period of ports in male and female patients was $458.8 \pm 449.3$ and $658.7 \pm 535.7$ days, respectively $(p<0.0001)$.

Table 1. Patient characteristics (male versus female).

\begin{tabular}{cccc}
\hline Variables & \multicolumn{2}{c}{$n \mathbf{( \% )}$ or Mean \pm SD } & \multirow{2}{*}{$\boldsymbol{p}$ Value } \\
\cline { 2 - 3 } & Male & Female & \\
\hline Age & $59.6 \pm 12.8$ & $57.3 \pm 12.8$ & $<0.0001$ \\
Body height & $165.8 \pm 7.2$ & $154.9 \pm 6.9$ & $<0.0001$ \\
Body weight & $64.4 \pm 11.8$ & $55.8 \pm 10.4$ & $<0.0001$ \\
Body mass index & $23.4 \pm 3.8$ & $23.2 \pm 4.0$ & 0.2941 \\
\hline Malignancy & & & \\
Head and neck & $264(15.4 \%)$ & $38(3.07 \%)$ & $<0.0001$ \\
Thorax & $653(38.1 \%)$ & $621(50.20 \%)$ & $<0.0001$ \\
Abdomen & $662(38.6 \%)$ & $471(38.08 \%)$ & 0.7536 \\
Pelvis & $7(0.4 \%)$ & $6(0.49 \%)$ & 0.7572 \\
Soft tissue & $9(0.5 \%)$ & $8(0.65 \%)$ & 0.6675 \\
Hematology & $146(8.5 \%)$ & $104(8.41 \%)$ & 0.9114 \\
Other & $15(0.9 \%)$ & $6(0.49 \%)$ & 0.2130 \\
\hline Side & & & \\
Right & $1618(94.4 \%)$ & $1022(82.6 \%)$ & $<0.0001$ \\
Left & $95(5.6 \%)$ & $215(17.4 \%)$ & \\
\hline Entry route & $1683(98.2 \%)$ & $1222(98.8 \%)$ & 0.2388
\end{tabular}


Table 1. Cont.

\begin{tabular}{|c|c|c|c|}
\hline \multirow{2}{*}{ Variables } & \multicolumn{2}{|c|}{$n(\%)$ or Mean $\pm \mathrm{SD}$} & \multirow{2}{*}{$p$ Value } \\
\hline & Male & Female & \\
\hline \multicolumn{4}{|l|}{ Entry vessel } \\
\hline Cephalic vein & $1467(85.7 \%)$ & $1034(83.6 \%)$ & \multirow{4}{*}{0.0632} \\
\hline Thoracoacromial vein & $177(10.3 \%)$ & $149(12.0 \%)$ & \\
\hline IJV $^{2}$ & $36(2.1 \%)$ & $39(3.2 \%)$ & \\
\hline Other ${ }^{3}$ & $33(1.9 \%)$ & $15(1.2 \%)$ & \\
\hline \multicolumn{4}{|l|}{ Port type } \\
\hline B'Braun Fr. 6.5 & $528(30.8 \%)$ & $331(26.7 \%)$ & \multirow{4}{*}{0.0100} \\
\hline Bard X Fr.6/8 & $408(23.8 \%)$ & $357(28.9 \%)$ & \\
\hline Bard power Fr. 6 & $544(31.8 \%)$ & $388(31.4 \%)$ & \\
\hline Polysite Fr.7 & $233(13.6 \%)$ & $161(13.0 \%)$ & \\
\hline \multicolumn{4}{|l|}{ Operation method } \\
\hline Vessel cutdown & $1085(63.4 \%)$ & $785(63.5 \%)$ & \multirow{7}{*}{$<0.0001$} \\
\hline Wire assistance without puncture & $394(23.0 \%)$ & $208(16.8 \%)$ & \\
\hline Wire assistance with puncture & $173(10.1 \%)$ & $180(14.5 \%)$ & \\
\hline Wire and venogram assistance & & & \\
\hline a. Without puncture & $7(0.4 \%)$ & $6(0.5 \%)$ & \\
\hline b. Puncture & $19(1.1 \%)$ & $18(1.5 \%)$ & \\
\hline Echo guide puncture & $35(2.0 \%)$ & $40(3.2 \%)$ & \\
\hline \multicolumn{4}{|l|}{ Operation time (Minutes) } \\
\hline Vessel cutdown & $26.4 \pm 10.7$ & $28.6 \pm 10.8$ & $<0.0001$ \\
\hline Wire assistance without puncture & $29.9 \pm 10.7$ & $30.5 \pm 10.3$ & 0.4947 \\
\hline Wire assistance with puncture & $39.2 \pm 14.9$ & $41.5 \pm 16.6$ & 0.1748 \\
\hline \multicolumn{4}{|l|}{ Wire and venogram assistance } \\
\hline a. Without puncture & $32.4 \pm 11.1$ & $34.2 \pm 8.9$ & 0.7635 \\
\hline b. Puncture & $48.9 \pm 17.0$ & $48.3 \pm 16.4$ & 0.9038 \\
\hline Echo guide puncture & $62.0 \pm 12.6$ & $60.2 \pm 22.2$ & 0.6585 \\
\hline \multicolumn{4}{|l|}{ Post-op quality } \\
\hline Catheter-nut angle $\left({ }^{\circ}\right)$ & $169.7 \pm 7.7$ & $170.0 \pm 7.2$ & 0.1926 \\
\hline Tip location $(\mathrm{cm})$ & $1.0 \pm 1.4$ & $1.4 \pm 1.5$ & $<0.0001$ \\
\hline Functional period (days) & $458.8 \pm 449.3$ & $658.7 \pm 535.7$ & $<0.0001$ \\
\hline \multicolumn{4}{|l|}{ Follow-up status } \\
\hline Alive & $949(55.4 \%)$ & $864(69.9 \%)$ & $<0.0001$ \\
\hline Expired & $514(30.0 \%)$ & $254(20.5 \%)$ & \\
\hline Discharged Against advice & $250(14.6 \%)$ & $119(9.6 \%)$ & \\
\hline
\end{tabular}

${ }^{1}$ Forty-three male patients have diagnosed double cancers, 17 female patients have diagnosed double cancers. ${ }^{2}$ IJV: internal jugular vein. ${ }^{3}$ Other: 38 right greater saphenous veins, 7 left greater saphenous veins, 1 right axillary vein, 2 right external jugular veins.

\subsection{Procedure and Late Complications}

Overall complication rate was $3.08 \%$ with an incidence of 0.057 episodes per 1000 catheter days. Only two patients were identified with port rotation, which resulted from the cutting through of thin pectoralis major muscle by the stay suture during postural movement. No pneumothorax, hematoma, catheter kinking, catheter fracture, or pocket erosion was identified. Procedure-related complication rate was $0.07 \%$ (Table 2). The complication rates of migration, malfunction, infection, and deep vein thrombosis (DVT) were $0.68 \%, 0.54 \%, 1.29 \%$, and $0.51 \%$, respectively. The incidences of port rotation, migration, malfunction, infection, and DVT were $0.001,0.012,0.010,0.024$, and 0.009 per 1000 catheter days, respectively (Table 2). Compared with our previous study, procedurerelated complications were nearly completely eliminated except for port rotation Table S2. Late complication rate and incidence were markedly lower compared with our previous study (Figure 2A,B). Relative risk ratios of migration, malfunction, infection, and DVT were $0.288,0.148,0.137$, and 0.432 , respectively (Figure 2C). 
Table 2. Complication rate, incidence, and reason for re-intervention.

\begin{tabular}{|c|c|c|c|c|c|c|c|c|c|c|c|}
\hline \multirow{2}{*}{$\begin{array}{c}\text { Entry Vessel } \\
\text { Number of patients }\end{array}$} & \multicolumn{2}{|c|}{ Cephalic Vein } & \multicolumn{2}{|c|}{$\begin{array}{c}\text { Thoracoacromial } \\
\text { Vein }\end{array}$} & \multicolumn{2}{|c|}{$\begin{array}{c}\text { Internal Jugular } \\
\text { Vein }\end{array}$} & \multicolumn{2}{|c|}{ Other } & \multicolumn{2}{|c|}{$\begin{array}{c}\text { Greater Saphenous } \\
\text { Vein }\end{array}$} & \multirow{2}{*}{$\begin{array}{l}\text { Total } \\
2950 \\
\end{array}$} \\
\hline & 2242 & 259 & 296 & 30 & 61 & 14 & 48 & 0 & 38 & 7 & \\
\hline $\begin{array}{c}\text { Side of } \\
\text { Complication }\end{array}$ & Right & Left & Right & Left & Right & Left & Right & Left & Right & Left & 91 \\
\hline \multicolumn{12}{|l|}{ Procedure related } \\
\hline $\begin{array}{l}\text { Rotation } \\
\text { Late }\end{array}$ & 1 & 0 & 0 & 0 & 1 & 0 & 0 & 0 & 0 & 0 & 2 \\
\hline Infection & 29 & 3 & 4 & 0 & 1 & 0 & 0 & 0 & 1 & 0 & 38 \\
\hline Malfunction & 7 & 1 & 2 & 0 & 2 & 0 & 2 & 0 & 1 & 1 & 16 \\
\hline Migration & 16 & 0 & 3 & 0 & 0 & 0 & 1 & 0 & 0 & 0 & 20 \\
\hline $\begin{array}{l}\text { Deep vein } \\
\text { thrombosis }\end{array}$ & 10 & 4 & 1 & 0 & 0 & 0 & 0 & 0 & 0 & 0 & 15 \\
\hline \multicolumn{12}{|c|}{ Complication Rate } \\
\hline Entry Vessel & \multicolumn{2}{|c|}{ Cephalic Vein } & \multicolumn{2}{|c|}{$\begin{array}{c}\text { Thoracoacromial } \\
\text { Vein }\end{array}$} & \multicolumn{2}{|c|}{$\begin{array}{c}\text { Internal Jugular } \\
\text { Vein }\end{array}$} & \multicolumn{2}{|c|}{ Other } & \multicolumn{2}{|c|}{$\begin{array}{c}\text { Greater Saphenous } \\
\text { Vein }\end{array}$} & Total \\
\hline Number of patients & 2242 & 259 & 296 & 30 & 61 & 14 & 3 & 0 & 38 & 7 & 2950 \\
\hline Side/Total rate & Right & Left & Right & Left & Right & Left & Right & Left & Right & Left & $3.08 \%$ \\
\hline $\begin{array}{c}\text { Procedure related } \\
\text { Rotation } \\
\text { Late }\end{array}$ & $0.04 \%$ & 0 & 0 & 0 & $1.64 \%$ & 0 & 0 & 0 & 0 & 0 & $0.07 \%$ \\
\hline Infection & $1.29 \%$ & $1.16 \%$ & $1.35 \%$ & 0 & $1.64 \%$ & 0 & 0 & 0 & $2.63 \%$ & 0 & $1.29 \%$ \\
\hline Malfunction & $0.31 \%$ & $0.39 \%$ & $0.68 \%$ & 0 & $3.28 \%$ & 0 & $4.16 \%$ & 0 & $2.63 \%$ & $14.29 \%$ & $0.54 \%$ \\
\hline Migration & $0.71 \%$ & 0 & $1.01 \%$ & 0 & 0 & 0 & $2.08 \%$ & 0 & 0 & 0 & $0.68 \%$ \\
\hline $\begin{array}{l}\text { Deep vein } \\
\text { thrombosis }\end{array}$ & $0.45 \%$ & $1.54 \%$ & $0.34 \%$ & 0 & 0 & 0 & 0 & 0 & 0 & 0 & $0.51 \%$ \\
\hline \multicolumn{12}{|c|}{ Incidence } \\
\hline Entry Vessel & \multicolumn{2}{|c|}{ Cephalic Vein } & \multicolumn{2}{|c|}{$\begin{array}{c}\text { Thoracoacromial } \\
\text { Vein }\end{array}$} & \multicolumn{2}{|c|}{$\begin{array}{l}\text { Internal Jugular } \\
\text { Vein }\end{array}$} & \multicolumn{2}{|c|}{ Other } & \multicolumn{2}{|c|}{$\begin{array}{c}\text { Greater Saphenous } \\
\text { Vein }\end{array}$} & Total \\
\hline $\begin{array}{l}\text { Sum of catheter } \\
\text { days }\end{array}$ & $1,188,218$ & 180,844 & 145,804 & 23,159 & 38,196 & 8788 & 4945 & 0 & 8612 & 2142 & $1,600,708$ \\
\hline $\begin{array}{l}\text { Side/Total } \\
\text { incidence }\end{array}$ & Right & Left & Right & Left & Right & Left & Right & Left & Right & Left & 0.057 \\
\hline $\begin{array}{l}\text { Procedure related } \\
\text { Rotation } \\
\text { Late }\end{array}$ & 0.001 & 0 & 0 & 0 & 0.026 & 0 & 0 & 0 & 0 & 0 & 0.001 \\
\hline Infection & 0.024 & 0.017 & 0.027 & 0 & 0.026 & 0 & 0 & 0 & 0.116 & 0 & 0.024 \\
\hline Malfunction & 0.006 & 0.006 & 0.014 & 0 & 0.052 & 0 & 0.404 & 0 & 0.116 & 0.467 & 0.010 \\
\hline Migration & 0.013 & 0 & 0.021 & 0 & 0 & 0 & 0.202 & 0 & 0 & 0 & 0.012 \\
\hline $\begin{array}{l}\text { Deep vein } \\
\text { thrombosis }\end{array}$ & 0.008 & 0.022 & 0.007 & 0 & 0 & 0 & 0 & 0 & 0 & 0 & 0.009 \\
\hline
\end{tabular}




\subsection{Evolution of Operation Method and Operative Time}

From 2012 to 2018, an increasing number of procedures was done by vessel cutdown $(p=0.0146)$ (Table 3). The percentage of procedures using vessel cutdown increased from approximately $60 \%$ in earlier years to $74.3 \%$ in 2018 . In addition, echo-guided IJV highneck puncture markedly declined from $4.7 \%$ to $1.0 \%(p=0.027)$. The highest percentage $(27.2 \%)$ of wire assistance without puncture was reported in 2013 , and gradually decreased thereafter. The variation trend in operative time was further analyzed using Loess smooth curve and linear regression models and showed gradual decline from $37.88 \mathrm{~min}$ to $23.20 \mathrm{~min}$. In the linear regression curve model, the operation time also declined from $34.33 \mathrm{~min}$ to $22 \mathrm{~min}$ (Figure 2D).
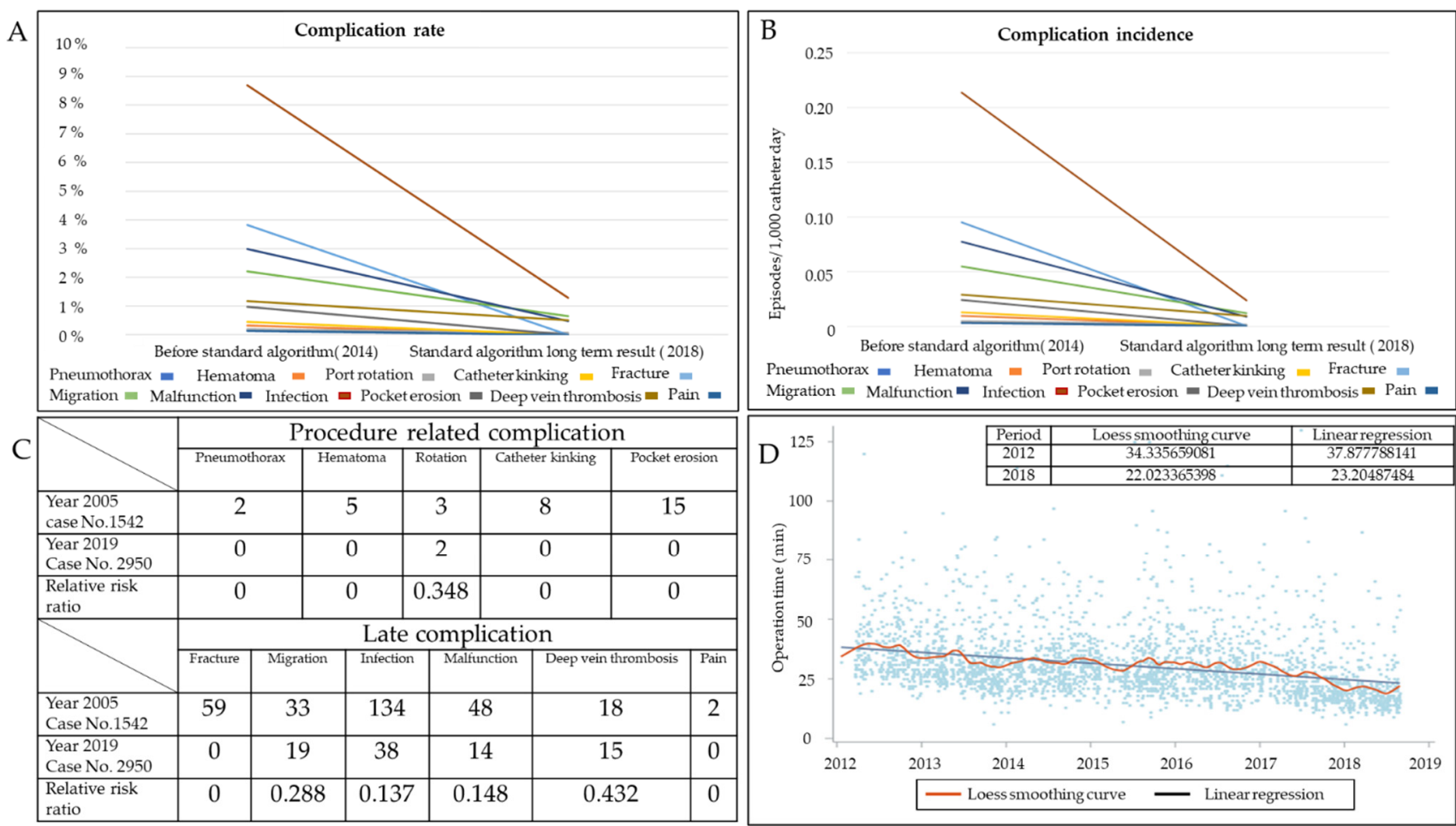

Figure 2. Variation trends of complication rate, incidence, and operation. (A) Variation trends of procedure- and catheterrelated complication rates. (B) Variation trend of procedure- and catheter-related complication incidences. (C) Relative risk ratio between Year 2005 and Year 2018 cohorts. (D) Variation trend of operation time. 
Table 3. Evolution of operation method and operative time.

\begin{tabular}{|c|c|c|c|c|c|c|c|c|}
\hline Case Number & 2012 & 2013 & 2014 & 2015 & 2016 & 2017 & 2018 & $p$ Value $^{\text {a }}$ \\
\hline Vessel cutdown & $211(65.7 \%)$ & $313(59.5 \%)$ & $304(61.3 \%)$ & $277(60.8 \%)$ & $283(66.4 \%)$ & $257(60.9 \%)$ & $225(74.3 \%)$ & 0.0146 \\
\hline Wire assistance without puncture & $57(17.8 \%)$ & $143(27.2 \%)$ & $113(22.8 \%)$ & $90(19.7 \%)$ & $73(17.1 \%)$ & $80(19.0 \%)$ & $46(15.2 \%)$ & 0.0014 \\
\hline Wire assistance with puncture & $38(11.8 \%)$ & $52(9.9 \%)$ & $64(12.9 \%)$ & $78(17.1 \%)$ & $50(11.7 \%)$ & $52(12.3 \%)$ & $19(6.3 \%)$ & 0.3424 \\
\hline $\begin{array}{l}\text { Wire and venogram assistance } \\
\text { a. Without puncture } \\
\text { b. Puncture }\end{array}$ & $\begin{array}{l}0(0.00 \%) \\
0(0.00 \%)\end{array}$ & $\begin{array}{l}0(0.00 \%) \\
0(0.00 \%)\end{array}$ & $\begin{array}{l}1(0.2 \%) \\
1(0.2 \%)\end{array}$ & $\begin{array}{l}0(0.0 \%) \\
3(0.7 \%)\end{array}$ & $\begin{array}{l}3(0.7 \%) \\
9(2.1 \%)\end{array}$ & $\begin{array}{c}8(1.9 \%) \\
15(3.5 \%)\end{array}$ & $\begin{array}{l}1(0.3 \%) \\
9(3.0 \%)\end{array}$ & - \\
\hline Echo guide puncture & $15(4.7 \%)$ & $18(3.4 \%)$ & $13(2.6 \%)$ & $8(1.7 \%)$ & $8(1.9 \%)$ & $10(2.4 \%)$ & $3(1.0 \%)$ & 0.0027 \\
\hline Operation Time & 2012 & 2013 & 2014 & 2015 & 2016 & 2017 & 2018 & $p$ Value $^{\mathrm{b}}$ \\
\hline Vessel cutdown & $34.2 \pm 10.5$ & $28.9 \pm 8.8$ & $29.7 \pm 10.2$ & $28.5 \pm 11.7$ & $27.8 \pm 10.3$ & $22.8 \pm 9.6$ & $18.5 \pm 7.5$ & $<0.0001$ \\
\hline Wire assistance without puncture & $38.8 \pm 9.5$ & $33.0 \pm 9.3$ & $31.7 \pm 10.2$ & $29.9 \pm 11.2$ & $29.0 \pm 7.6$ & $23.5 \pm 9.4$ & $20.4 \pm 6.1$ & $<0.0001$ \\
\hline Wire assistance with puncture & $48.1 \pm 11.2$ & $45.1 \pm 12.9$ & $41.5 \pm 15.4$ & $38.8 \pm 15.4$ & $40.6 \pm 16.2$ & $36.1 \pm 19.1$ & $25.2 \pm 7.0$ & $<0.0001$ \\
\hline $\begin{array}{c}\text { Wire and venogram assistance } \\
\text { a. Without puncture } \\
\text { b. Puncture }\end{array}$ & - & - & $\begin{array}{l}43.0 \text { * } \\
58.0 \text { * }\end{array}$ & $\begin{array}{c}- \\
70.7 \pm 21.8\end{array}$ & $\begin{array}{l}27.7 \pm 11.0 \\
50.8 \pm 15.1\end{array}$ & $\begin{array}{l}33.9 \pm 10.0 \\
45.9 \pm 15.2\end{array}$ & $\begin{array}{c}35.0 * \\
42.7 \pm 14.9\end{array}$ & - \\
\hline Echo guide puncture & $59.3 \pm 23.0$ & $61.0 \pm 21.4$ & $60.1 \pm 7.6$ & $67.7 \pm 16.2$ & $67.1 \pm 22.6$ & $53.3 \pm 11.3$ & $64.7 \pm 20.1$ & 0.9509 \\
\hline
\end{tabular}

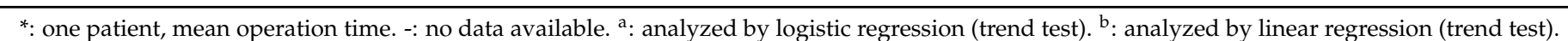




\section{Discussion}

In the study cohort, disease distribution was similar in both sexes except for thoracic malignancy and head and neck cancers. More female patients had thoracic malignancy, since we categorized breast cancer as a thoracic malignancy $(p<0.0001)$, whereas more male patients had head and neck cancers. These differences may have led to more left-side implantations $(p<0.0001)$ and slightly deeper catheter tip locations $(p<0.001)$ in females compared to males. The variations in operation method may be related to the variations in individual entry vessels, such as three-dimensional spatial orientation of blood vessels and vessel caliber. More high-neck echo-guided IJV puncture was reported in female patients because of inadequate vessel quality.

In this study, we used the coracoid process of the scapula as a landmark for incision, thus minimizing incision variation $[20,22]$. In addition, vessel cutdown was the preferred method and the cephalic vein was the target vessel for port implantation because of its low complication rate $[15,23]$. In patients with inaccessible cephalic vein, the thoracoacromial vein may serve as an alternative choice [8,24]. In addition, anatomic variations such as small vessel caliber and tortuous path may prohibit direct catheter implantation. To overcome these difficulties and to minimize IJV puncture, endovascular techniques (Figures S2 and S3) may be employed for assistance. With the aid of these endovascular techniques, port implantation can be done even when the quality of the entry vessel is suboptimal. Echo-guided high-neck IJV puncture was reserved only for patients with no accessible vessels. These differences not only eliminated pneumothorax, arterial puncture, and catheter fracture but also reduced IJV puncture from $4.7 \%$ to less than $1.0 \%(p=0.027)$. With the aid of the standard algorithm, average operative time gradually decreased in each subsequent year for all methods $(p<0.0001)$, and this trend was confirmed using Loess smooth and linear regression curve models.

The pocket was created of adequate size along the avascular plane between the pectoralis major muscle fascia and subcutaneous tissue. This strategy not only preserved the whole layer of subcutaneous tissue but also avoided catheter impingement. By adhering to the algorithm, hematoma, port erosion, impingement-related fracture [25], and malfunction were markedly decreased [6]. Intra-operative fluoroscopy not only allowed real-time monitoring of port implantation, it also helped to standardize the catheter-nut angle and to optimize the tip location [5,6]. Migration was minimized by optimal tip location; however, it still occurred because the intravascular portion of the catheter was free within the vessel to move upward with increased intrathoracic pressure [20,26]. Quality control was achieved by standardized operative procedures and planning, the use of intra-operative fluoroscopy monitoring, and post-operative chest plain film confirmation. Low complication rate and incidence and stable implantation quality were re-confirmed, revealing the reproducibility of the standard algorithm.

There are some limitations to this study. This study was a retrospective study; however, the large number of cases who received intravenous port implantation by the standard algorithm allowed for homogeneity in the management of the whole study cohort and reliable results. Second, a functional intravenous port not only relies on good implantation quality but also depends on good maintenance strategy, and this may explain why infection and malfunction remained, even after the standard algorithm was implemented in practice. Appropriate irrigation volume and maintenance strategy may be needed to reduce the occurrence $[27,28]$ and further investigation is warranted. Third, posture variations resulting in changes of vascular caliber may confound the analysis of DVT occurrence. From the literature review, the occurrence of DVT has been associated with catheter-vessel caliber ratio, i.e., cross-sectional area of catheter/cross-sectional area of vessel [29]. Lengthening of the subclavian vein and, thus, a decrease in catheter-vessel caliber ratio can result during stretch posture and result in DVT. Further investigations are warranted. Despite these limitations, the study not only shows that the standard algorithm for port implantation works to minimize complications, but it also confirms its reproducibility. 


\title{
5. Conclusions
}

The proposed standard algorithm and the described surgical planning and techniques may help surgeons minimize the occurrence of complications related to intravenous port implantation.

Supplementary Materials: The following are available online at https:/ /www.mdpi.com/article/ 10.3390/jpm11050344/s1, Figure S1: Patients disposition diagram, Figure S2: Wire assistance with venography to overcome small vessel caliber, Figure S3: Wire assistance with venography to overcome sharp angle at confluence site between cephalic and subclavian vein, Table S1: Patient characteristics (Whole cohort), Table S2: Complication rates and incidence between Year 20057 and Year 2018.

Author Contributions: Conceptualization, C.-F.W., J.-Y.F., and C.-Y.W.; methodology, C.-F.W., J.-Y.F., and C.-Y.W.; software, C.-T.W., C.-H.C., M.-J.H., Y.-H.L., and H.-P.L.; validation, C.-Y.W.; formal analysis, C.-F.W., J.-Y.F., and C.-Y.W.; investigation, C.-F.W., J.-Y.F., C.-T.W., C.-H.C., M.-J.H., Y.-H.L., H.-P.L., and C.-Y.W.; resources, C.-T.W., C.-H.C., M.-J.H., Y.-H.L., and H.-P.L.; data curation, C.-F.W., J.-Y.F., C.-T.W., C.-H.C., M.-J.H., Y.-H.L., H.-P.L., and C.-Y.W.; writing - original draft preparation, C.F.W. and J.-Y.F.; writing - review and editing, C.-Y.W.; visualization, C.-F.W., J.-Y.F., C.-T.W., C.-H.C., M.-J.H., Y.-H.L., H.-P.L., and C.-Y.W.; supervision, J.-Y.F. and C.-Y.W.; project administration, J.-Y.F. and C.-Y.W.; funding acquisition, J.-Y.F. All authors have read and agreed to the published version of the manuscript.

Funding: This research was funded by Chang Gung Medical Foundation under grant number CMRPG5G013. The APC was funded by Chang Gung Medical Foundation.

Institutional Review Board Statement: The study was conducted according to the guidelines of the Declaration of Helsinki, and approved by the Institutional Review Board of Chang Gung Medical Foundation under the approval number 201800329B0.

Informed Consent Statement: Patients' signed, informed consent was obtained before enrollment.

Data Availability Statement: The data presented in this study are available on request from the corresponding author. The data are not publicly available due to limitation of Personal Data Protection Act of Taiwan.

Conflicts of Interest: The authors declare no conflict of interest.

\begin{abstract}
Abbreviations
IJV: internal jugular vein; SVC: superior vena cava; IVC: inferior vena cava; GSV: greater saphenous vein; picture archiving and communication system (PACS); anterior inferior iliac spine (ASIS); deep vein thrombosis (DVT).
\end{abstract}

\section{References}

1. Seo, T.-S.; Song, M.G.; Kang, E.-Y.; Lee, C.H.; Yong, H.S.; Doo, K. A Single-Incision Technique for Placement of Implantable Venous Access Ports via the Axillary Vein. J. Vasc. Interv. Radiol. 2014, 25, 1439-1446. [CrossRef]

2. Iorio, O.; Gazzanelli, S.; D’Ermo, G.; Pezzolla, A.; Gurrado, A.; Testini, M.; De Toma, G.; Cavallaro, G. A Prospective, Comparative Evaluation on Totally Implantable Venous Access Devices by External Jugular Vein versus Cephalic Vein Cutdown. Am. Surg. 2018, 84, 841-843. [CrossRef] [PubMed]

3. Plumhans, C.; Mahnken, A.H.; Ocklenburg, C.; Keil, S.; Behrendt, F.F.; Günther, R.W.; Schoth, F. Jugular versus subclavian totally implantable access ports: Catheter position, complications and intrainterventional pain perception. Eur. J. Radiol. 2011, 79, 338-342. [CrossRef]

4. Wu, C.-Y.; Fu, J.-Y.; Feng, P.-H.; Kao, T.-C.; Yu, S.-Y.; Li, H.-J.; Ko, P.-J.; Hsieh, H.-C. Catheter Fracture of Intravenous Ports and its Management. World J. Surg. 2011, 35, 2403-2410. [CrossRef] [PubMed]

5. Wu, C.-Y.; Fu, J.-Y.; Feng, P.-H.; Liu, Y.-H.; Kao, T.-C.; Yu, S.-Y.; Ko, P.-J.; Hsieh, H.-C. Risk Factors and Possible Mechanisms of Intravenous Port Catheter Migration. Eur. J. Vasc. Endovasc. Surg. 2012, 44, 82-87. [CrossRef] [PubMed]

6. Wu, C.-Y.; Hu, H.C.; Ko, P.J.; Fu, J.Y.; Wu, C.F.; Liu, Y.H.; Li, H.J.; Kao, T.-C.; Yu, S.-Y.; Chang, C.J.; et al. Risk factors and possible mechanisms of superior vena cava intravenous port malfunction. Ann. Surg. 2012, 255, 971-975. [CrossRef] [PubMed]

7. Wu, C.-F.; Ko, P.-J.; Liu, Y.-H.; Kao, T.-C.; Yu, S.-Y.; Li, H.-J.; Hsieh, H.-C. A single-center study of vascular access sites for intravenous ports. Surg. Today 2014, 44, 723-731. [CrossRef] [PubMed] 
8. Su, T.W.; Wu, C.F.; Fu, J.Y.; Ko, P.J.; Yu, S.Y.; Kao, T.C.; Hiseih, H.-C.; Wu, C.Y. Deltoid branch of thoracoacromial vein: A safe alternative entry vessel for intravenous port implan-tation. Medicine 2015, 94, e728. [CrossRef] [PubMed]

9. Hong, S.; Seo, T.-S.; Song, M.G.; Seol, H.-Y.; Suh, S.I.; Ryoo, I.-S. Clinical outcomes of totally implantable venous access port placement via the axillary vein in patients with head and neck malignancy. J. Vasc. Access 2018, 20, 134-139. [CrossRef] [PubMed]

10. Song, M.G.; Seo, T.S.; Kim, Y.H.; Cho, S.B.; Chung, H.H.; Lee, S.H.; Jung, E. Effect of catheter diameter on left innominate vein in breast cancer patients after totally im-plantable venous access port placement. J. Vasc. Access 2018, 19, 615-619. [CrossRef] [PubMed]

11. Sun, X.; Bai, X.; Shen, J.; Yu, Z.; Zhuang, Z.; Jin, Y. Comparison between ultrasound-guided TIVAD via the right innominate vein and the right inter-nal jugular vein approach. BMC Surg. 2019, 19, 189. [CrossRef]

12. Ku, Y.-H.; Kuo, P.-H.; Tsai, Y.-F.; Huang, W.-T.; Lin, M.-H.; Tsao, C.-J. Port-A-Cath Implantation Using Percutaneous Puncture Without Guidance. Ann. Surg. Oncol. 2008, 16, 729-734. [CrossRef]

13. Yanık, F.; Karamustafaoğlu, Y.A.; Karataş, A.; Yörük, Y. Experience in totally implantable venous port catheter: Analysis of 3000 patients in 12 years. Turk. J. Thorac. Cardiovasc. Surg. 2018, 26, 422-428. [CrossRef] [PubMed]

14. Velioğlu, Y.; Yüksel, A.; Sınmaz, E. Complications and management strategies of totally implantable venous access port inser-tion through percutaneous subclavian vein. Turk. J. Thorac. Cardiovasc. Surg. 2019, 27, 499-507. [CrossRef] [PubMed]

15. Di Carlo, I.; Pulvirenti, E.; Mannino, M.; Toro, A. Increased use of percutaneous technique for totally implantable venous access de-vices. Is it real progress? A 27-year comprehensive review on early complications. Ann Surg Oncol. 2010, 17, 1649-1656. [CrossRef] [PubMed]

16. Wei, W.C.; Wu, C.Y.; Wu, C.F.; Fu, J.Y.; Su, T.W.; Yu, S.Y.; Ko, P.J. The Treatment Results of a Standard Algorithm for Choosing the Best Entry Vessel for Intrave-nous Port Implantation. Medicine 2015, 94, e1381. [CrossRef] [PubMed]

17. Lee, J.H.; Kim, Y.B.; Lee, M.K.; Kim, J.I.; Lee, J.Y.; Lee, S.Y.; Lee, E.-J.; Lee, Y.S. Catastrophic hemothorax on the contralateral side of the insertion of an implantable subcla-vian venous access device and the ipsilateral side of the removal of the infected port-A case report. Korean J. Anesthesiol. 2010, 59, 214-219. [CrossRef] [PubMed]

18. Sarach, J.; Zschokke, I.; Melcher, G.A. A Life-Threatening Mediastinal Hematoma after Central Venous Port System Implanta-tion. Am. J. Case Rep. 2015, 16, 904-907. [CrossRef] [PubMed]

19. Aitken, D.R.; Minton, J.P. The "pinch-off sign": A warning of impending problems with permanent subclavian catheters. Am. J. Surg. 1984, 148, 633-636. [CrossRef]

20. Wu, C.Y.; Fu, J.Y.; Wu, C.F. SVC port catheter tip confirmation: Quantified formula for intravascular catheter length versus anatomic landmark reference. Ann. Vasc Surg. 2019, 60, 193-202. [CrossRef] [PubMed]

21. Wu, C.-Y.; Fu, J.-Y.; Ko, P.-J.; Liu, Y.-H.; Kao, T.-C.; Yu, S.-Y. Dose Intraoperative Fluoroscopy Precisely Predict Catheter Tip Location via Superior Vena Cava Route? Medicine 2015, 94, e2199. [CrossRef] [PubMed]

22. Hashimoto, S.; Otsubo, R.; Adachi, M.; Doi, R.; Shibata, K.; Sano, I.; Shibata, Y.; Nakazaki, T.; Taniguchi, H.; Nagayasu, T. Cephalic Vein Cut-down for Totally Implantable Central Venous Access Devices With Preoperative Ultrasonography by Surgical Residents. Vivo 2019, 33, 2079-2085. [CrossRef] [PubMed]

23. De Sousa, B.; Furlanetto, J.; Hutka, M.; Gouveia, P.; Wuerstlein, R.; Mariz, J.M.; Pinto, D.; Cardoso, F.L. Central venous access in oncology: ESMO Clinical Practice Guidelines. Ann. Oncol. 2015, 26, v152-v168. [CrossRef] [PubMed]

24. Povoski, S.P. A prospective analysis of the cephalic vein cutdown approach for chronic indwelling central venous access in 100 consecutive cancer patients. Ann. Surg. Oncol. 2000, 7, 496-502. [CrossRef] [PubMed]

25. Wu, C.; Fu, J.; Cheng, C.; Liu, Y.; Ko, P.; Liu, Y.; Chu, Y. Initial experiences with a new design for a preattached intravenous port device. J. Biomed. Mater. Res. Part. B Appl. Biomater. 2018, 106, 1017-1027. [CrossRef]

26. Fu, J.Y.; Wu, C.F.; Ko, P.J.; Wu, C.Y.; Kao, T.C.; Yu, S.Y.; Liu, Y.-H.; Hsieh, H.-C. Analysis of chest X-ray plain film images of intravenous ports inserted via the superior vena cava. Surg. Today 2014, 44, 1513-1521. [CrossRef] [PubMed]

27. Wu, C.Y.; Cheng, C.H.; Fu, J.Y.; Chu, Y.; Wu, C.F.; Chiu, C.H.; Ko, P.-J.; Liu, Y.-H. Recommended irrigation volume for an intravenous port: Ex vivo simulation study. PLoS ONE 2018, 13, e0201785. [CrossRef]

28. Chou, P.-L.; Fu, J.-Y.; Cheng, C.-H.; Chu, Y.; Wu, C.-F.; Ko, P.-J.; Liu, Y.-H. Current port maintenance strategies are insufficient: View based on actual presentations of implanted ports. Medicine 2019, 98, e17757. [CrossRef] [PubMed]

29. Spencer, T.R.; Mahoney, K.J. Reducing catheter-related thrombosis using a risk reduction tool centered on catheter to vessel ratio. J. Thromb. Thrombolysis 2017, 44, 427-434. [CrossRef] 